Jul 1st, 12:00 AM

\title{
Environment Explorer: Spatial Support System for the Integrated Assessment of Socio-economic and Environmental Policies in the Netherlands
}

\author{
Guy Engelen
}

Inge Uljee

Roger White

Follow this and additional works at: https://scholarsarchive.byu.edu/iemssconference

Engelen, Guy; Uljee, Inge; and White, Roger, "Environment Explorer: Spatial Support System for the Integrated Assessment of Socioeconomic and Environmental Policies in the Netherlands" (2002). International Congress on Environmental Modelling and Software. 267. https://scholarsarchive.byu.edu/iemssconference/2002/all/267

This Event is brought to you for free and open access by the Civil and Environmental Engineering at BYU ScholarsArchive. It has been accepted for inclusion in International Congress on Environmental Modelling and Software by an authorized administrator of BYU ScholarsArchive. For more information, please contact scholarsarchive@byu.edu, ellen_amatangelo@byu.edu. 


\title{
Environment Explorer: Spatial Support System for the Integrated Assessment of Socio-economic and Environmental Policies in the Netherlands
}

\author{
Guy Engelen $^{1}$, Inge Uljee ${ }^{1}$, and Roger White ${ }^{2}$ \\ ${ }^{1}$ Research Institute for Knowledge Systems bv, P.O. Box 463, 6200 AL Maastricht, The Netherlands \\ gengelen@riks.nl; \\ ${ }^{2}$ Department of Geography, Memorial University of Newfoundland, St. John's, NF, Canada A1B $3 X 9$.
}

\begin{abstract}
Environment Explorer is a system developed to support spatial scientists, planners and decision makers at the regional and national level in the Netherlands to analyse a wide range of social, economic and environmental policies and their associated spatial patterns. The core of this system consists of linked dynamic spatial models operating at both the micro- and the macro-geographical scales. At the macro scale, the modelling framework integrates several component sub-models, representing the natural, social, and economic sub-systems. At the micro level, cellular automata based models determine the faith of individual parcels of land based on institutional, physical and environmental factors as well as on the type of activities in their neighbourhoods. The approach enables the straightforward integration of detailed physical, environmental, and institutional variables as well as the particulars of the transportation infrastructure, and permits a very detailed and integral representation of the evolving spatial system. In the policy support system the models are supplemented with dedicated tools for interactive design, analysis and evaluation of policy interventions and scenarios. This system covers the entire territory of the Netherlands and represents processes at the national, the regional (40 administrative regions), and the cellular ( 25 ha cells) levels. It runs on top of detailed GIS information and generates future land use and land cover for the period 2000 till 2030. The quality of the alternatives tried out is expressed in some 40 economic, social and environmental indicators available in the model as dynamic maps. The application has been developed over the past 5 years. It has been used at the national and the provincial level for the preparation of spatial policy documents. Some conclusions relative to the development and the use of the system are presented.
\end{abstract}

Keywords: integrated assessment, spatial modelling, policy support system

\section{IF ONLY WE KNEW...}

With a population of 16 million living on 40,000 $\mathrm{km}^{2}$ of land, the Netherlands is a small and densely populated country. It is primarily a large Delta shaped by the Rhine, Meuse, and Scheldt rivers. No less than 5 million people live on some 8,500 $\mathrm{km}^{2}$ of land that is at or below sea level. Of course they live behind dikes and are protected from the sea and the rivers, however, in a country that is troubled by the sinking of the land due to tectonic movements and continued oxidation of the peat substrate, and increasing amounts of water running down the main rivers. Yet, the Netherlands is one of the only Western European countries that still have a growing population and consequently an ever-increasing demand for space.
In the given circumstances strict policies and control on how the limited available land is used seconded by an alert and elaborate monitoring system and a set of state of the art tools for the development and exploration of strategies and policies to tackle threats detected, is the best available to keep the country afloat. With the increasing amount of stress exerted on the system and the complexities of the problems posed, the needs for appropriate planning instruments change rapidly too. In particular the need for instruments supporting a truly integrated approach to spatial planning problems is very urgent. This paper presents one such instrument --named Environment Explorer (EE)-- developed to design, explore, and evaluate long-term policies relative to the development of the physical environment in the Netherlands in an economic, social and ecological context. The development of EE started 
in 1997 (De Nijs et al., 2001). Since then, it has evolved into a powerful Policy Support System for integrated spatial planning, supported by the National Institute for Public health and the Environment, as well as the National Institute for Marine and Coastal Management, the National Institute for Inland Water Management and Waste Water Treatment, and the Transport Research Centre of the Ministry of Transport, Public Works and Water Management. It is a highly interactive, transparent instrument enabling the development and evaluation of a large set of alternatives currently used at the National and the Provincial levels for developing spatial planning strategies.

\section{AN INTEGRATED SPATIAL MODEL OF THE NETHERLANDS}

The core component of $\mathrm{EE}$ is an explicitly dynamic land use-transportation model applied to the full territory. In order to represent the processes that make and change the spatial configuration of the country, it features a layered model representing processes operating at three geographical levels: the National (1 region), the Regional (40 administrative regions) and the Local (351000 cellular units 25 ha each) (see Figure 1) (Engelen et al., 1995; 1999).

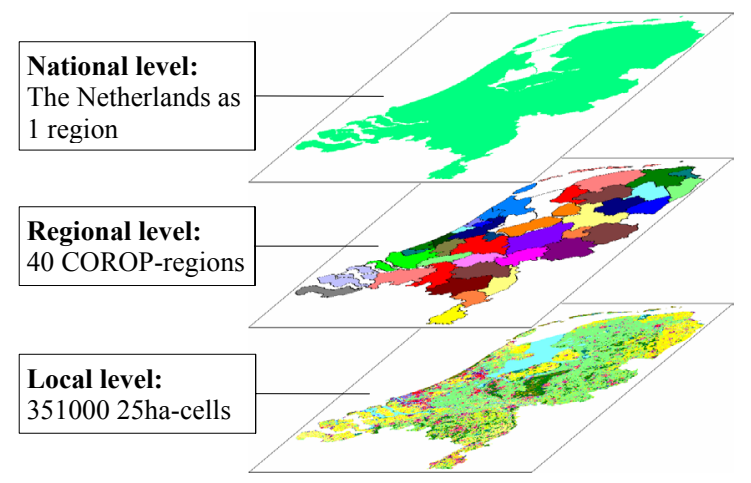

Figure 1. The Environment Explorer model represents processes at three spatial levels: National, Regional and Local.

At the National level, the model integrates national figures taken from economic and demographic growth scenarios considering developments in the Netherlands in the context of Europe and the world beyond. From these, growth figures for the national population and the activity per economic sector are derived and entered into the model as trend lines. They are an input for the models at the regional level.

The economic activities are condensed into eight main categories: crop farming, dairy farming, greenhouse farming, other farming, industry, services, socio-cultural activities, and recreation. The population is assigned to two residential categories: high and low-density residential.

The choice of the categories is based on their distinct spatial requirements and specific behaviour, the quality, match, and availability of data at the three geographical levels of the model, and last but not least the end-use requirements of the model.

Next, at the Regional level consisting of 40 large administrative regions (called COROP regions), a classic dynamic spatial interaction based model (Wilson, 1974; White, 1977, 1978; Allen and Sanglier, 1979a, 1979b;) arranges for the allocation of national growth as well as for the interregional migration of activities and residents based on the relative attractiveness of the regions. The attractiveness of a region is determined by its importance as a centre of economic activity and housing, its position relative to the other regions, its position relative to the neighbouring countries, its access points to distant markets via the main air- and seaports, and its position in the public and the private transportation systems. Next to these, and novel in the context of interaction based models, detailed information relative to the quality of the space internal to the regions, obtained from the models at the local level, is also considered. One of two principles is applied: (1) for activities such as housing, a relative potential calculation is applied, (2) for other activities, such as services, for which economic considerations are more important; a relative profit criterion is applied.

Four sub-models can be distinguished:

A regional economic module (1) calculates the amount of production and employment for each economic activity, its allocation and re-allocation among the regions.

A regional demographic module (2) deals with the demand for housing, its allocation and reallocation among the regions.

A transportation module (3), --in fact a four-stage transportation model-- deals with the growth of the mobility, the changes in the quality and capacity of the transportation infrastructure, and calculates intensity and congestion on the transportation networks. These elements affect the long-term migration of activities and residents as well as the short-term movement of goods and people between the different regions.

A land-claim module (4) translates the regional growth numbers into spatial claims. The latter are passed on to the model at the local (cellular) level for a detailed allocation. Two principles are applied at this level: (1) claim for land is fixed and passed on as a hard constraint. This principle 
reflects the fact that for particular activities policies determine the amount and location of land that is to be created or to be preserved in a region. It applies mostly for land uses such as natural land, recreational land, and some of the agricultural activities. Or, (2) the principle of supply and demand is applied to regulate the densification of land use as well as its spatial allocation. This principle applies in particular to housing and most of the economic activities.

At the Local level the detailed allocation of economic activities and people is modelled by means of a Cellular Automata based land use model (Couclelis, 1985; White and Engelen, 1993, 1997; Batty and Xie, 1994;). To that effect, the Netherlands is represented as a mosaic of 351000 grid cells of 25 ha each ( $500 \mathrm{~m}$ on the side). Together they constitute the land use pattern of the country. Land use is classified in 17 categories, 10 of which are land use functions modelled dynamically. This model is driven by the demands for land per region generated at the regional level. In fact there are 40 identical cellular models running in parallel: one for each region. Four elements determine whether a piece of land (each 25 ha cell) is taken in by a particular land use function or not (see Figure 2):

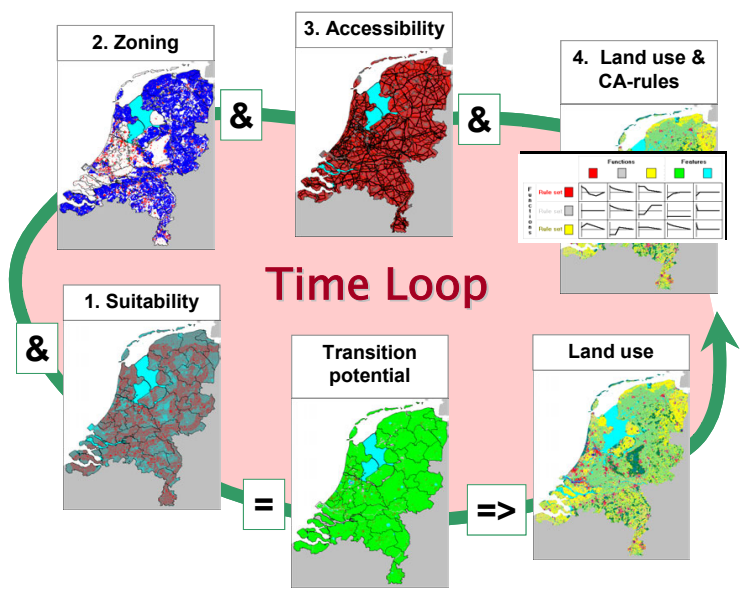

Figure 2. 4 elements determine the dynamics at the local level

(1) The physical suitability. Suitability is represented in the model by one map per land use function modelled. It is a composite measure, prepared in a Geographical Information System (GIS), on the basis of some 15 factor maps determining the physical, ecological and environmental appropriateness of cells to support a land use function and the associated economic or residential activity. Factors are among others: elevation, soil quality, agricultural capacity, air quality, noise pollution, etc.
(2) The zoning or institutional suitability. Zoning too is characterized by one map per land use function. It is a composite measure based on master plans and planning documents available from the national or regional planning authorities and containing among others ecologically valuable and protected areas, protected culturescapes, buffer areas, etc. For three planning periods, to be determined by the user (example: 2000-2005, 2005-2015, and 2015-2030), they specify which cells can and can not be taken in by each land use;

(3) The accessibility. The accessibility for each land use function is calculated in the model relative to the transportation system consisting of: the railways and railway stations, the navigable waterways, and the road network (the LMS-road network used by the Ministry of Transport, Public Works and Water Management) consisting of the motorways, main national, and regional roads. It is an expression of the ease with which an activity can fulfil its needs for transportation and mobility in a particular cell. It accounts for: the distance of the cell to the nearest link or node, the quality of that link, and the needs for transportation of the particular activity or land use function.

(4) Dynamics at the Local level. While the above three elements are introduced into the model to determine the non-homogeneous nature of the physical space within which the land use dynamics unfold, there is a fourth and important aspect, namely the dynamic impact of land uses in the immediate surrounding of a location. This is no longer the domain of abstract planning either, but that of the reality on the ground representing the fact that the presence of complementary or competing activities and desirable or repellent land uses is of great significance for the quality of that location and thus for its appeal to particular activities. For each location, the model assesses the quality of its neighbourhood: a circular area with a radius of $4 \mathrm{~km}$ containing the 196 nearest cells. For each land use function, a set of rules determines the degree to which it is attracted to, or repelled by, the other functions present in the neighbourhood. The strength of the interactions as a function of the distance separating the different functions within the neighbourhood is articulated in the rules. If the attractiveness is high enough, the function will try to occupy the location, if not, it will look for more attractive places. New activities and land uses invading a neighbourhood over time will thus change its attractiveness for activities already present and others searching for space. This process explains the decay of a residential neighbourhood due to the invasion by industrial or commercial activities, as well as the revival of decayed neighbourhoods initiated by the 
arrival of few high quality functions like parks, exclusive office buildings, high-end condominiums, etc. The rules determining the interactions between the different functions: the inertia, the push and pull forces, and economies of scale, are defined as part of the calibration of the model.

On the basis of these four elements, the model calculates for every simulation step the transition potential for each cell and function. In the course of time and until regional demands are satisfied, cells will change to the land use function for which they have the highest potential. Consequently, the transition potentials reflect the pressures exerted on the land and thus constitute important information to those responsible for the design of sound spatial planning policies.

The linkage between the models at the National, Regional and Local levels is bi-directional and very intense: the national growth figures are imposed as constraints on the regional models, the regional models will distribute and allocate the national growth to the 40 regions and will impose on the cellular models the regional growth numbers. The cellular models will finally determine at the highest level of detail where the growth is likely to take place. In this process, the cellular models return to the regional models information on the quality and the availability of space for further expansion of each type of economic or residential activity. This information is an input into the spatial interaction calculations at the regional level and it will influence strongly the relative attractiveness of the individual regions. As regions in the course of time are gradually running out of space for one or the other activity, they will lose part of their competitive edge and will exert less attraction. Growth is consequently diverted to other, more attractive regions.

\section{USING ENVIRONMENT EXPLORER FOR INTEGRATED PLANNING}

\subsection{State variables and Indicators}

From the model description, it is clear that EE generates output at the Regional and the Local levels. Typically the model is run for the 30-year period between 2000 and 2030, but other time intervals are possible too. Results are calculated and visualized on a yearly basis. At the regional level, the population, as well as the employment and production figures in each economic sector are calculated. At the Local level the resulting new land use map is generated for every simulated year. In addition to these, and based on the regional and local state variables, the model calculates some 40 spatial indicators expressing changes in the economic, social, or environmental status of the country, the regional and cellular entities. Together they constitute important information relative to the merits of one or the other project, policy or strategy tried out with EE. Each indicator is in itself a more or less elaborate sub-model that may require additional information introduced into EE. Indicators include among others: access to employment (economic), cost of land (economic), build-up area (social), open space (social), recreational space per inhabitant (social), noise pollution and emissions due to traffic (environmental), congestion on the road system (economic), flooding risk (social), residential density (social), spatial fragmentation (environmental, see Figure 3), etc. Like the other state variables, indicators are calculated on a yearly basis and are available in EE in the form of dynamic maps, time charts and numeric output.

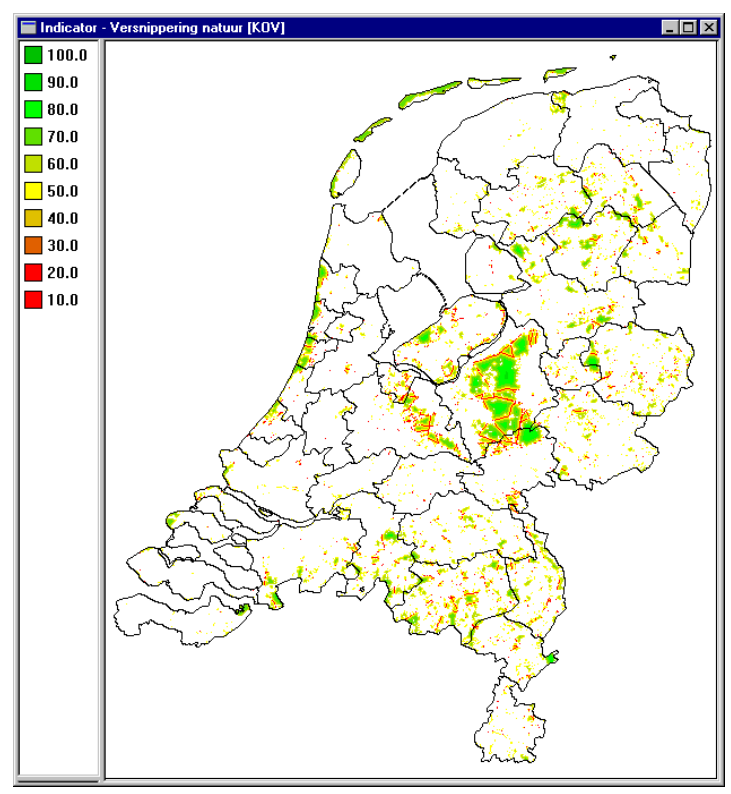

Figure 3. The degree of spatial fragmentation of natural areas calculated as an indicator in EE.

\subsection{Scenarios, Strategies and Projects: interventions in the spatial structure}

EE has been designed for use as an analytical tool: it offers analytic capabilities to policy makers in government departments ranging from the municipal to the national levels. But, it has an important role as a tool for communication too: it should stimulate collaboration, discussion and consultation among the different planning institutions and departments. That is why the instrument has been equipped with a state of the art graphical user interface (Figure 4), providing access to all the variables, parameters and maps used at every level of detail. This offers the users 
the ability to create and enter policy variants interactively by defining and adjusting values within a preset range of values and context. Over and above economic and demographic scenarios, which can be stated by means of dedicated dialogs, tables and graphs, the model can take into account spatial scenarios, such as those proposed by various government departments and entered in the form of alternative sets of numbers and maps. The suitability and zoning maps as well as the transportation networks are available in the model with the appropriate editors enabling interactive changes by the user so that infrastructure projects or particular policy decisions on opening or closing areas for development can be tried out experimentally. Thus the visions and strategies as options for future spatial, economic and social policies, proposed by the individual governmental institutions are pooled and presented into detailed spatial blueprints of the Netherlands and translated into relevant societal terms. Their impacts and effectiveness in the short and long term future of the country is calculated, visualized, and available for further analysis and discussion.

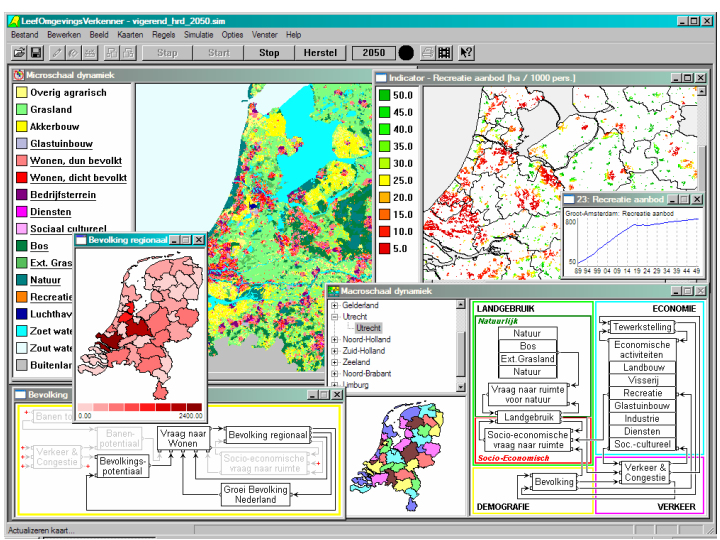

Figure 4. Environment Explorer is equipped with a state of the art graphical user-interface.

In order to construct, amend and evaluate integrated spatial strategies and scenarios, a number of additional cartographic tools are available. In particular, and for preparing input maps, EE is equipped with the so-called OVERLAY-TOOL, an instrument geared at the creation of the Suitability and Zoning maps used at the Local level of the model. It takes (factor) maps from GIS as an input and combines them into a single composite map by weighing the relative importance of the information represented on the maps. The weights are set interactively through the manipulation of sliders on the screen. The composite map changes accordingly and instantly. The output can be exported straightforwardly into EE or back into the GIS if desired. The OverlayTool is of particular use in interactive sessions with stakeholders and representatives of different planning departments as it focuses the discussion on the importance of particular factors in the determination of the appropriateness of areas for one or the other use. The ANALYSE-TOOL is an instrument enabling the comparison of the many maps generated in EE, containing categorical data or data on a ratio or ordinal scale. It is an essential instrument for comparing the spatial effects of the alternatives generated and for evaluating their specific merits against preset criteria.

\subsection{An extensive analysis}

The prime purpose of EE is to represent at a high level of abstraction the autonomous dynamics that change the face of the Netherlands. Actual and intended policies and plans are introduced. They constrain and steer this autonomous growth. Confronted with adverse trends and growth of the system in economic, social or environmental terms, the planner can intervene and change existing policies or define new ones in an effort to bring the system onto a more favourable path of development. The many features of EE are specifically intended for this purpose and support the user in his search for a better or more acceptable evolution of the system. The integrated nature of $\mathrm{EE}$ enables analysing direct but also indirect consequences of interventions, its dynamic nature enables exploring immediate effects, but also those that become visible at a later stage, and the spatial nature enables evaluating impacts at the national, the regional and the local scale.

\section{AN EVALUATION}

Now that the system is in its fifth year of existence, a number of conclusions can be drawn relative to its development and use.

Overall, the appropriateness of EE as an analytical instrument for the design and evaluation of spatial plans as well as a tool for communication about such plans is granted by most users at the provincial and the national levels. EE provides insight in the interconnected nature of different functions, processes and cause effect relations. It makes the effects of policy interventions explicit in the domain of the user but also in that of colleagues and counterparts. EE enables to calculate fast, and consequently more, alternatives than would normally be considered or possible and it enables an objective evaluation of the results generated. However, EE represents a complex and complicated system. Consequently it is difficult to keep the system itself from being complicated, and despite the fact that major effort has gone into 
rendering it as transparent and user-friendly as possible, it only meets the expectations of part of its intended end-users on this subject. Mostly technicians, more familiar with GIS and models, that have worked their way trough the documentation are happy with the system as it is. For occasional and non-technical users this is much less the case. That is why sessions, involving groups of specialists working as a team on national or regional planning documents, have been facilitated or assisted by the developers of the system.

Instruments like EE depend largely on good quality data. In particular a high-resolution land use map is required for the base year of the model, but also for years in the past in order to determine trends, calibrate and validate the model. This is a problem because good land use maps are rare. Most often the detail, the number, and the choice of the land use categories are insufficient to be useful. Moreover, the definitions and categories change over time and making the land use maps consistent between years becomes a laborious prerequisite. Next, the match between on the one hand the land use categories of the land use map (at the Local level) and on the other hand the activity classes (at the Regional and National levels) represented in economic and census tables, is not necessarily one to one. Very often it will be necessary to go back to the most fine-grained representation of the census data in order to establish a workable match.

The calibration and validation of the type of model is far from easy or fast. This is partly due to the limited availability of good quality data, but also to the integrated nature of the model: all linked processes need to be calibrated in isolation and in combination in order to generate reliable results. Moreover, it has been the experience of EE that the model needs to be recalibrated regularly when additional processes are build-in or when better data become available. An automated or semiautomated calibration procedure is much wanted to take care of this problem. For EE such procedure is under development (Straatman et al., in press).

Finally, EE is a very data intensive system. This is true for the base data required to set-up the system but also for the definition of the scenarios, strategies and alternatives tried out. The system facilitates handling these with great ease, yet it is important to have a good (meta-) documentation method to keep track of the data used in the exercises carried out.

\section{REFERENCES}

Allen P. and M. Sanglier, A Dynamical Model of Growth in a Central Place System, Geographical Analysis, 11, 256-272, 1979a.

Allen P. and M. Sanglier, A Dynamic Model of a central Place System-II, Geographical Analysis, 13. 149-164, 1979b.

Batty M. and Y. Xie, From cells to cities, Environment and Planning B, 21, 31-48, 1994.

Couclelis H., Cellular Worlds: A Framework for Modelling Micro-Macro Dynamics, Environment and Planning A, 17, 585-596, 1985.

De Nijs T., G. Engelen, R. White, H. van Delden, and I. Uljee, De LeefOmgevingsVerkenner. Technische documentatie, RijksInstituut voor Volksgezondheid en Milieuhygiene, Bilthoven, Report 408505007/2001, 2001.

Engelen G., R. White, I. Uljee and P. Drazan, Using Cellular Automata for Integrated Modelling of Socio-environmental Systems, Environmental monitoring and Assessment, 30, 203-214, 1995.

Engelen, G., S. Geertman, P. Smits, and C. Wessels, Dynamic GIS and Strategic Physical Planning: A Practical Application, in: Geographical Information and Planning. Advances in Spatial science, edited by: J. Stillwell, S. Geertman, and S. Openshaw, Springer, Berlin, 87-111, 1999.

Straatman B., G. Engelen, and R. White (In Press), Towards an Automatic Calibration Procedure for Constrained Cellular Automata, Computers Environment and Urban Systems.

White R., Dynamic Central Place Theory: Results of a Simulation Approach, Geographical Analysis, 9, 227-243, 1977.

White, R., The simulation of Central Place Dynamics: Two Sector Systems and the Rank-Size Distribution, Geographical Analysis, 10, 201-208, 1978.

White R. and G. Engelen, Cellular Automata and Fractal Urban Form: A Cellular Modelling Approach to the Evolution of Urban Land Use Patterns, Environment and Planning A, 25, 1175-1199, 1993.

White R. and G. Engelen, Cellular Automata as the Basis of Integrated Dynamic Regional Modelling, Environment and Planning B, 24, 235-246. 1997.

Wilson, A.G., Urban and Regional Models in Geography and Planning, John Wiley and Sons, London, 1974. 